\title{
Evaluation of the knowledge, attitude, and behaviors of physicians and pharmacists regarding the use of medicines in pregnancy
}

\author{
Mevhibe TAMIRCI ${ }^{1}$ (D), Ahmet AKICI 1 * (D), Volkan AYDIN 1 (D), Sibel SAKARYA ${ }^{2}$ (D), \\ Mehmet Zafer GOREN ${ }^{1}$ (D)
}

1 Department of Medical Pharmacology, Faculty of Medicine, Marmara University, Maltepe 34854 İstanbul, Turkey.

2 Department of Public Health, Faculty of Medicine, Koç University, Sariyer 34450 İstanbul, Turkey.

* Corresponding Author. E-mail: ahakici@gmail.com (A.A.) ; Tel. +90 2164212222.

Received: 17 June 2020 / Revised: 23 December 2020 / Accepted: 16 January 2021

\begin{abstract}
Pregnancy is a critical aspect of rational use of medicine (RUM) and imposes important responsibilities on the parties. This study aimed to analyze the knowledge, attitudes, and behaviors of the physicians and pharmacists regarding pharmacotherapy in pregnancy. The data were collected between April 2016-July 2017 by questionnaires and analyses of the prescriptions in Northern Cyprus. Simulated prescriptions $(n=50)$ for pregnant women $(P W)$ were applied at pharmacies, and pharmacists' $(n=95)$ and obstetricians' $(n=30)$ attitudes were evaluated through surveys. In addition, PW prescriptions ( $\mathrm{n}=122)$ were collected from pharmacies and evaluated. All data were re-obtained after one year. The mean number of drugs per PW prescription was $1.48 \pm 0.73$. In teratogenicity risk evaluation, $6.6 \%$ of medicines were in " $\mathrm{D} / \mathrm{X}$ " and $16.7 \%$ were in " $\mathrm{C}$ " categories. The ratio of these three categories medicines in scripts was about eight times higher than which was considered as teratogenic based on physicians' opinions. Serious shortcomings were found in writing the format information in prescriptions. In simulated prescription analysis, mean dispensing time was $3.3 \pm 2.3 \mathrm{~min}$. Almost half of the pharmacists were observed to give the drug requested by simulated PW without any confirmation of the prescription. The dispensing performances of the pharmacists were mainly different than their related statements on the survey. Our study highlighted the deficiencies in physicians' and pharmacists' RUM knowledge, attitudes, and behaviors in pregnancy, where the gaps seem unchanged after one year. These findings underline necessity of education and counselling service interventions for healthcare providers to disseminate RUM in pregnancy.
\end{abstract}

KEYWORDS: Pharmacist; pregnancy; prescriber; prescription simulation; teratogenicity.

\section{INTRODUCTION}

Ethical and many other clinical reasons restrict conduction of clinical trials in pregnant women (PW) to very confined conditions in special settings. Although this issue has been tried to overcome with preclinical studies, it is not always possible to extrapolate these results to humans. In this context, pharmacoepidemiological studies play an important role in filling this gap. Mostly, it is not possible to avoid drug exposure during pregnancy completely. Many studies in literature reported PW's exposure to various drugs, ranging between 50-95.5\% [1-4]. In fact, use of medicines in pregnancy should be considered according to the "benefit/risk" ratio of the drug, in line with the rational use of medicine (RUM) principles by all stakeholders.

World Health Organization (WHO) defined RUM as "patients receive medications appropriate to their clinical needs, in doses that meet their own individual requirements, for an adequate period of time, and at the lowest cost to them and their community" [5]. Pregnancy is definitely one of the most special cases of the RUM that should be applied rigorously and carefully to maximize the benefits for mother and the fetus, also reducing the potential risks. Drug utilization in pregnancy can vary widely between countries and regions. There are no comprehensive studies in the Northern Cyprus (NC) regarding RUM in pregnancy. In the NC, according to the last census, the $52.6 \%$ of the permanent residents were women in a total population of around 300,000 people [6]. In the NC, a total of 78 obstetricians and 184 community pharmacists are registered in the

How to cite this article: Tamirci M, Akici A, Aydin V, Sakarya S, Gören MZ. Evaluation of the knowledge, attitude, and behaviours of physicians and pharmacists regarding the use of medicines in pregnancy. J Res Pharm. 2021; 25(2): 218-229. 
relevant professional associations, in 2016. In this study, we aimed to determine the knowledge, attitudes, and behaviors of the physicians and pharmacists about medicine use in pregnancy in the NC.

\section{RESULTS}

\subsection{Prescription analysis}

The mean number of drugs per PW prescription was $1.48 \pm 0.73$. None of these prescriptions comprised patient's age or gestation time, and only $2.5 \%$ included a diagnosis. For drugs, the most commonly used information was about the dosage $(83.9 \%)$ and the least the strength $(18.3 \%)$. These and other characteristics of prescriptions were also similarly observed in the prescriptions collected in the re-examination performed one year later ( $p>0.05)$, (Online Supplement-1).

The most frequently prescribed drugs were found as "folic acid" (11.2\%) and "multivitamins/minerals" (11.2\%). These were followed by "progesterone" (5.5\%), "iron-III-hydroxide-polymaltose complex" (4.3\%), "imidazole-derivatives" (3.9\%), "iron-II-glycine-sulphate complex" (2.8\%), "cyanocobalamin combinations" $(2.8 \%)$, and "ornidazole" $(2.8 \%)$. The re-examination exhibited a similar prescribing frequency, especially for the top three drugs (Table 1 ).

Pregnancy risk category showed majority of prescribed drugs to belong to " $\mathrm{A}$ " (\%40.0) or " $\mathrm{B}$ " (\%22.8). The percentage of " $\mathrm{D}$ " and " $\mathrm{X}$ " category drugs, found as $3.3 \%$ and $3.3 \%$, respectively, in the first examination were also similarly detected in the re-examination $(2.4 \%$ and $3.1 \%$, respectively; $p>0.05$, Figure 1$)$. The distribution of the prescribed drugs by ATC- 1 and ATC- 3 classifications was summarized at Table 2 .

In the first examination, the most commonly prescribed drugs at ATC-3 level were "vitamin B12 and folic-acid" (B03B, 13.9\%) and "multivitamins" (A11A, 11.1\%). The drugs in category-X were detected as "estrogens" (16.7\%), "progestogens" (33.3\%), and "gonadotropins and other ovulation stimulants" (50.0\%), and those in category-D were as "antithrombotics", "estrogens", and "tetracyclines" (33.3\% for each; Table 2).

The most prescribed drugs at ATC-5 level in each category were as follows: "folic acid" and "multivitamins/minerals" (\%27.8 for both) in category-A, "progesterone" (24.4\%) in category-B, "imidazolederivatives" (\%23.3) in category-C, "acetylsalicylic acid", "estriol", and "doxycycline" (33.3\% for each) in category-D, and "clomiphene" and "medroxyprogesterone" (33.2\% for both) in category-X. A similar pattern on the most commonly prescribed drugs in each category was observed at the re-examination $(p>0.05)$.

\subsection{Dispensing of simulation prescription}

The mean duration of prescription dispensing by the 50 pharmacists for PW-simulated prescriptions were found as $3.3 \pm 2.3 \mathrm{~min}$ in the first and $2.0 \pm 0.8 \mathrm{~min}$ in the second examination $(\mathrm{p}<0.05)$. Fifty percent of the pharmacists were observed to accept the simulated requests of $\mathrm{PW}$ which was to get trimethobenzamide instead of the already prescribed "vitamin/mineral-containing antiemetic". None of these pharmacists gave the patient information about drug's strength, duration of use, and storage conditions, with only $4.8 \%$ providing information about the pharmaceutical form and the dosage. It was observed that $100 \%(n=50), 98 \%$ $(n=49)$ and $96 \%(n=48)$ of the pharmacists did not provide information to the patient about the diagnosis, the adverse effects, and the possible effects of the drug on the fetus, respectively; and only $10 \%$ questioned the gestational week. Besides, no pharmacist was found to ask about use of "other concurrent drug, nonprescribed drug, herbal product, or alcohol" and smoking habits or to provide information on food interactions. In the re-examination, the pharmacists were observed to exhibit similar behaviors for each of the above findings in the simulation. It was observed that 20 pharmacists $(40.0 \%)$ in the first examination and 23 pharmacists $(46.0 \%)$ in the re-examination had attempted to give PW another drug that was claimed as a bioequivalent of the prescribed anti-emetic. This revealed that the most frequently suggested drugs by the pharmacists were "ondansetron" (32.1\%) and "diphenhydramine" $(28.6 \%)$ in the first examination; and "ondansetron" (37.2\%), "metoclopramide" (25.6\%), and "diphenhydramine" (20.9\%) in the re-examination. 


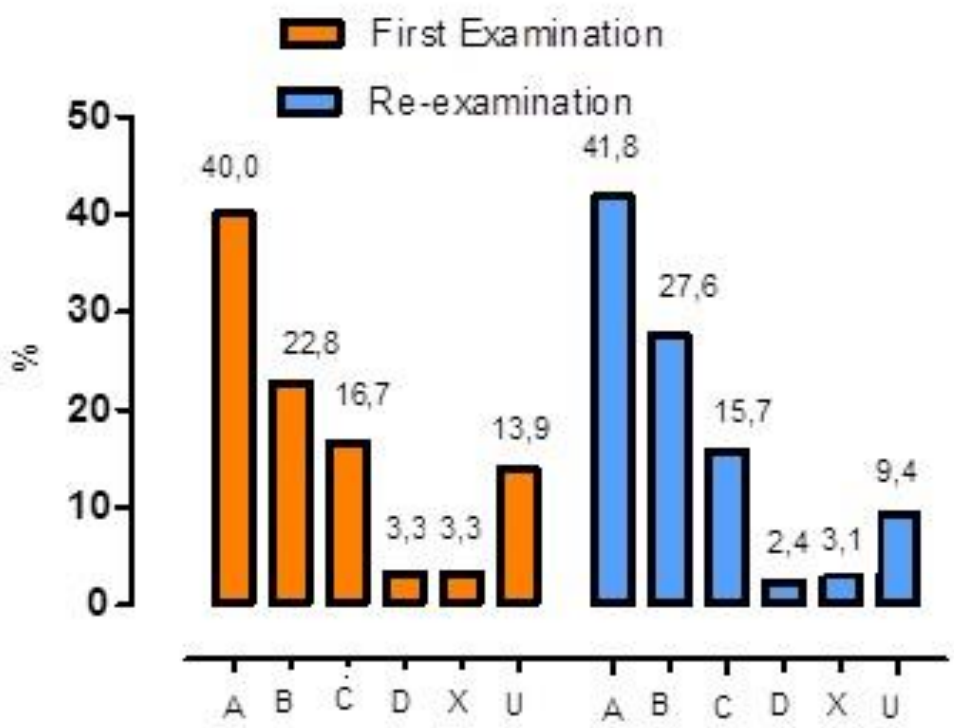

Figure 1. The first examination and one-year later re-examination distributions of prescribed drugs $(n=122$ and 98, respectively) according to FDA pregnancy risk classification.

\subsection{Physician survey}

Face-to-face surveys were conducted with 30 out of the 58 active obstetricians (response rate: $51.7 \%$ ). The majority $(70.0 \%)$ was male, the mean age was $50.8 \pm 11.1$, and the average duration of working as a specialist was $22.0 \pm 11.0$ years.

Physicians' observations showed that $78.2 \%$ of the PW attended regular follow-up visits, $71.8 \%$ had planned pregnancy, and $26.3 \%$ had received medical therapy for pregnancy. These physicians stated that $15.2 \%$ and $13.8 \%$ of the PW might have been used prescribed and non-prescribed drugs, respectively, when they became aware of their pregnancies. They also declared that $6.4 \%$ and $23.2 \%$ of the PW used prescribed drugs and non-pharmacological products (e.g. herbal product/supplements), respectively, during pregnancy. It was also stated that $33.9 \%$ of the PW worried about drug usage during their pregnancies. Only the thought of physicians regarding the non-pharmacological product use was different in the re-examination (31.1\%).

The physicians declared that most of the prescribed drugs (75.5\%) were "risk-free" in terms of teratogenicity, with also seldom prescriptions of "moderate-risk" (2.5\%) and "high-risk" (0.5\%) drugs in their practice. Physicians were observed to give similar responses to these statements in the re-examination.

Seventy percent of the physicians stated that they had encountered drug-induced miscarriage/abortion cases (most commonly due to ciprofloxacin) and $16.7 \%$ had seen drug-induced congenital abnormalities due to ciprofloxacin, fluconazole, or diethylstilbestrol use.

The attitudes of physicians, the provided information to their patients, and the mostly considered criteria while prescribing were evaluated by using Likert Scale. Accordingly, all physicians declared that they provided their patients with information about their diseases and explained the treatment objectives. In addition, they stated to consider the presence of other disorders, drug interactions, and gestational age during prescribing and to give their patients drug-related information, especially about administration route and treatment duration (Table 3).

Similar findings were observed in the re-examination. Both in the first and re-examination, the majority of the physicians $(60.0 \%$ and $75.0 \%$, respectively) pointed out that the most frequently used sources were "internet and obstetrician textbooks" while prescribing to the PW. In addition, $70.0 \%$ of the physicians stated their need for a practical and reliable drug information support service, and $83.3 \%$ of them declared that they want to receive clinical pharmacology information support service. 
Table 1. The distribution of the 30 most frequently prescribed drugs for pregnant women in the first and reexamination periods according to ATC-5 groups.

\begin{tabular}{|c|c|c|c|c|}
\hline Rank & $\begin{array}{l}\text { Drugs in first examination } \\
\text { (ATC Codes) }\end{array}$ & $\%(n)$ & Drugs in re-examination (ATC Codes) & $\%(n)$ \\
\hline 1 & Folic acid (B03BB01) & $11.1(20)$ & Folic acid (B03BB01) & $15.7(20)$ \\
\hline 2 & $\begin{array}{l}\text { Multivitamins and other minerals } \\
\text { (A11AA03) }\end{array}$ & $11.1(20)$ & $\begin{array}{l}\text { Multivitamins and other minerals } \\
\text { (A11AA03) }\end{array}$ & $7.8(10)$ \\
\hline 3 & Progesterone (G03DA04) & $5.5(10)$ & Progesterone (G03DA04) & $7.8(10)$ \\
\hline 4 & $\begin{array}{l}\text { Iron III Hydroxide Polymaltose } \\
\text { Complex (B03AD04) }\end{array}$ & $4.3(8)$ & Imidazole derivatives (G01AF20) & $7.8(10)$ \\
\hline 5 & Imidazole derivatives (G01AF20) & $3.9(7)$ & Cyanocobalamin combinations(B03BA51) & $6.3(8)$ \\
\hline 6 & $\begin{array}{l}\text { Iron (II) -glycine-sulfate-complex } \\
\text { (B03AE01) }\end{array}$ & $2.8(5)$ & Cefuroxime (J01DC02) & $3.9(5)$ \\
\hline 7 & $\begin{array}{l}\text { Cyanocobalamin combinations } \\
\text { (B03BA51) }\end{array}$ & $2.8(5)$ & Metoclopramide hydrochloride (A03FA01) & $3.1(4)$ \\
\hline 8 & Ornidazole (P01AB03) & $2.8(5)$ & $\begin{array}{l}\text { Iron III Hydroxide Polymaltose Complex } \\
\text { (B03AD04) }\end{array}$ & $3.1(4)$ \\
\hline 9 & Calcium (A12AA20) & $2.2(4)$ & Ondansetron (A04AA01) & $2.4(3)$ \\
\hline 10 & Iron protein succinylate (B03AD) & $2.2(4)$ & Amoxicillin + clavulanic acid (J01CR02) & $2.4(3)$ \\
\hline 11 & Enoxaparin sodium (B01AB05) & $1.7(3)$ & Fosfomycin (J01XX01) & $2.4(3)$ \\
\hline 12 & Fosfomycin (J01XX01) & $1.7(3)$ & Alginic acid (A02BX13) & $1.6(2)$ \\
\hline 13 & Alginic acid (A02BX13) & $1.7(3)$ & Acetylsalicylic acid (B01AC06) & $1.6(2)$ \\
\hline 14 & $\begin{array}{l}\text { Amoxicillin + clavulanic acid } \\
\text { (J01CR02) }\end{array}$ & $1.7(3)$ & $\begin{array}{l}\text { Iron (II)-glycine-sulfate-complex } \\
\text { (B03AE01) }\end{array}$ & $1.6(2)$ \\
\hline 15 & Cefuroxime (J01DC02) & $1.7(3)$ & Povidone Iodine (D08AG02) & $1.6(2)$ \\
\hline 16 & Fluconazole (J02AC01) & $1.7(3)$ & Paracetamol (N02BE01) & $1.6(2)$ \\
\hline 17 & Clotrimazole (G01AF02) & $1.7(3)$ & Medroxyprogesterone (G03DA02) & $1.6(2)$ \\
\hline 18 & $\begin{array}{l}\text { Metoclopramide hydrochloride } \\
\text { (A03FA01) }\end{array}$ & $1.1(2)$ & Estradiol (G03CA03) & $0.8(1)$ \\
\hline 19 & Dimenhydrinate (A04AD) & $1.1(2)$ & Clomiphene (G03GB02) & $0.8(1)$ \\
\hline 20 & Magnesium Citrate (A12CC04) & $1.1(2)$ & Estriol (G03CC06) & $0.8(1)$ \\
\hline 21 & Acetylsalicylic acid (B01AC06) & $1.1(2)$ & Gliclazide (A10BB09) & $0.8(1)$ \\
\hline 22 & Ethacridine lactate (D08AA01) & $1.1(2)$ & Nifedipine (C08CA05) & $0.8(1)$ \\
\hline 23 & Estriol (G03CC06) & $1.1(2)$ & Natamycin (G01AA02) & $0.8(1)$ \\
\hline 24 & Clomiphene (G03GB02) & $1.1(2)$ & Clotrimazole (G01AF02) & $0.8(1)$ \\
\hline 25 & Doxycycline (J01AA02) & $1.1(2)$ & Methenamine (J01XX05) & $0.8(1)$ \\
\hline 26 & Methenamine (J01XX05) & $1.1(2)$ & Ketoconazole (J02AB02) & $0.8(1)$ \\
\hline 27 & Medroxyprogesterone (G03DA02) & $1.1(2)$ & Fluconazole (J02AC01) & $0.8(1)$ \\
\hline 28 & Estradiol (G03CA03) & $0.6(1)$ & Itraconazole (J02AC02) & $0.8(1)$ \\
\hline 29 & Choriogonadotropin alfa (G03GA08) & $0.6(1)$ & Flurbiprofen (M01AE09) & $0.8(1)$ \\
\hline 30 & Itraconazole (J02AC02) & $0.6(1)$ & $\begin{array}{l}\text { Paracetamol + propyphenazone }+ \text { caffeine } \\
(\mathrm{N} 02 \mathrm{BE} 51)\end{array}$ & $0.8(1)$ \\
\hline \multirow[t]{2}{*}{31} & Other drugs & $26.6(48)$ & Other drugs & $17.3(22)$ \\
\hline & Total & $\begin{array}{l}100.0 \\
(180)\end{array}$ & Total & $100.0(127)$ \\
\hline
\end{tabular}

\subsection{Pharmacist survey}

Out of 120 pharmacists applied, 95 agreed to participate in the survey (response rate: $79.2 \%$ ). The majority of the pharmacists (65.3\%) were females, the mean age was $43.8 \pm 16.2$ years, and the mean duration of working as a community pharmacist was $17.2 \pm 14.2$ years. Based on pharmacists' statement, they were found to encounter a mean of 7.0 $55.1 \mathrm{PW}$ weekly. Pharmacists thought that their PW customers became aware of their pregnancies on average $4.8 \pm 2.1$ weeks of gestation. 
Table 2. The distribution of prescribed drugs for pregnant women in the first and re-examination periods according to ATC-1 and ATC-3 classifications.

\begin{tabular}{|c|c|c|c|c|c|c|c|c|c|c|c|c|c|c|c|}
\hline \multicolumn{16}{|c|}{ FDA risk classification of the drugs } \\
\hline \multirow{2}{*}{\multicolumn{2}{|c|}{$\begin{array}{c}\text { Drug } \\
\text { Classifications }\end{array}$}} & \multirow{2}{*}{$\begin{array}{l}\text { Total } \\
\%(n)\end{array}$} & \multicolumn{6}{|c|}{ First examination } & \multicolumn{6}{|c|}{ Re-examination } & \multirow{2}{*}{$\begin{array}{c}\mathrm{U} \\
\%(\mathrm{n})\end{array}$} \\
\hline & & & A & B & $\mathrm{C}$ & $\mathrm{D}$ & $\mathrm{x}$ & $\mathrm{U}$ & Total & A & B & $\mathrm{C}$ & D & $x$ & \\
\hline \multirow{7}{*}{$\vec{ن}$} & A & $\begin{array}{l}21.1 \\
(38)\end{array}$ & $\begin{array}{l}36.1 \\
(26)\end{array}$ & $\begin{array}{l}24.4 \\
(10)\end{array}$ & $\begin{array}{l}3.3 \\
(1)\end{array}$ & - & - & $\begin{array}{l}4.0 \\
(1)\end{array}$ & $\begin{array}{l}17.3 \\
(22)\end{array}$ & $\begin{array}{l}24.5 \\
(13)\end{array}$ & $\begin{array}{c}22.9 \\
(8)\end{array}$ & $\begin{array}{l}5.0 \\
(1)\end{array}$ & - & - & - \\
\hline & B & $\begin{array}{l}26.1 \\
(47)\end{array}$ & $\begin{array}{l}58.3 \\
(42)\end{array}$ & $\begin{array}{l}7.3 \\
(3)\end{array}$ & - & $\begin{array}{c}33.3 \\
(2)\end{array}$ & - & - & $\begin{array}{l}29.1 \\
(37)\end{array}$ & $\begin{array}{l}64.2 \\
(34)\end{array}$ & $\begin{array}{l}2.9 \\
(1)\end{array}$ & - & $\begin{array}{c}66.7 \\
(2)\end{array}$ & - & - \\
\hline & G & $\begin{array}{l}18.9 \\
(34)\end{array}$ & - & $\begin{array}{l}29.3 \\
(12)\end{array}$ & $\begin{array}{l}46.7 \\
(14)\end{array}$ & $\begin{array}{c}33.3 \\
(2)\end{array}$ & $\begin{array}{c}100.0 \\
(6)\end{array}$ & - & $\begin{array}{l}22.0 \\
(28)\end{array}$ & - & $\begin{array}{l}31.4 \\
(11)\end{array}$ & $\begin{array}{l}60.0 \\
(12)\end{array}$ & $\begin{array}{c}33.3 \\
\text { (1) }\end{array}$ & $\begin{array}{c}100.0 \\
(4)\end{array}$ & - \\
\hline & $\mathrm{J}$ & $\begin{array}{l}12.2 \\
(22)\end{array}$ & - & $\begin{array}{l}29.3 \\
(12)\end{array}$ & $\begin{array}{c}26.7 \\
(8)\end{array}$ & $\begin{array}{c}33.3 \\
(2)\end{array}$ & - & - & $\begin{array}{l}11.8 \\
(15)\end{array}$ & - & $\begin{array}{l}31.4 \\
(11)\end{array}$ & $\begin{array}{l}20.0 \\
(4)\end{array}$ & - & - & - \\
\hline & $\mathrm{V}$ & $\begin{array}{l}13.3 \\
(24)\end{array}$ & $\begin{array}{l}5.6 \\
(4)\end{array}$ & - & - & - & - & $\begin{array}{l}80.0 \\
(20)\end{array}$ & $\begin{array}{l}12.6 \\
(16)\end{array}$ & $\begin{array}{c}11.3 \\
(6)\end{array}$ & - & - & - & - & $\begin{array}{l}83.3 \\
(10)\end{array}$ \\
\hline & $\begin{array}{l}\text { Other } \\
\text { drugs }\end{array}$ & $\begin{array}{l}8.3 \\
(15)\end{array}$ & - & $\begin{array}{c}17.1 \\
(7)\end{array}$ & $\begin{array}{c}23.3 \\
(7)\end{array}$ & - & - & $\begin{array}{c}16.0 \\
(4)\end{array}$ & $7.1(9)$ & - & $\begin{array}{c}11.4 \\
(4)\end{array}$ & $\begin{array}{c}15.0 \\
\text { (3) }\end{array}$ & - & - & $\begin{array}{c}16.7 \\
(2)\end{array}$ \\
\hline & Total & $\begin{array}{l}100.0 \\
(180) \\
\end{array}$ & $\begin{array}{c}100.0 \\
(72) \\
\end{array}$ & $\begin{array}{c}100.0 \\
(41) \\
\end{array}$ & $\begin{array}{c}100.0 \\
(30) \\
\end{array}$ & $\begin{array}{c}100.0 \\
(6)\end{array}$ & $\begin{array}{c}100.0 \\
(6) \\
\end{array}$ & $\begin{array}{c}100.0 \\
(25) \\
\end{array}$ & $\begin{array}{l}100.0 \\
(127) \\
\end{array}$ & $\begin{array}{c}100.0 \\
(53) \\
\end{array}$ & $\begin{array}{c}100.0 \\
(35) \\
\end{array}$ & $\begin{array}{c}100.0 \\
(20) \\
\end{array}$ & $\begin{array}{c}100.0 \\
(3)\end{array}$ & $\begin{array}{c}100.0 \\
(4)\end{array}$ & $\begin{array}{c}100.0 \\
(12)\end{array}$ \\
\hline \multirow{7}{*}{ ? } & В03В & $\begin{array}{l}13.9 \\
(25)\end{array}$ & $\begin{array}{l}34.7 \\
(25)\end{array}$ & - & - & - & - & - & $\begin{array}{l}22.0 \\
(28)\end{array}$ & $\begin{array}{l}52.8 \\
(28)\end{array}$ & - & - & - & - & - \\
\hline & A11A & $\begin{array}{l}11.1 \\
(20)\end{array}$ & $\begin{array}{l}26.4 \\
(19)\end{array}$ & - & - & - & - & $4.0(1)$ & $\begin{array}{l}7.9 \\
(10)\end{array}$ & $\begin{array}{l}18.9 \\
(10)\end{array}$ & - & - & - & - & - \\
\hline & B03A & $\begin{array}{l}9.4 \\
(17)\end{array}$ & $\begin{array}{l}23.6 \\
(17)\end{array}$ & - & - & - & - & - & $4.7(6)$ & $\begin{array}{c}11.3 \\
(6)\end{array}$ & - & - & - & - & - \\
\hline & G01A & $\begin{array}{l}8.9 \\
(16)\end{array}$ & - & $\begin{array}{l}4.9 \\
(2)\end{array}$ & $\begin{array}{l}46.7 \\
(14)\end{array}$ & - & - & - & $\begin{array}{l}10.2 \\
(13)\end{array}$ & - & $\begin{array}{l}2.9 \\
(1)\end{array}$ & $\begin{array}{l}60.0 \\
(12)\end{array}$ & - & - & - \\
\hline & G03D & $\begin{array}{l}6.8 \\
(12)\end{array}$ & - & $\begin{array}{l}24.4 \\
(10)\end{array}$ & - & - & $\begin{array}{c}33.3 \\
(2)\end{array}$ & - & $\begin{array}{l}9.4 \\
(12)\end{array}$ & - & $\begin{array}{l}28.6 \\
(10)\end{array}$ & - & - & $\begin{array}{c}50.0 \\
(2)\end{array}$ & - \\
\hline & $\begin{array}{l}\text { Other } \\
\text { drugs }\end{array}$ & $\begin{array}{l}29.1 \\
(37)\end{array}$ & $\begin{array}{l}15.3 \\
(11)\end{array}$ & $\begin{array}{l}70.7 \\
(29)\end{array}$ & $\begin{array}{l}53.3 \\
(16)\end{array}$ & $\begin{array}{c}100.0 \\
(6)\end{array}$ & $\begin{array}{c}66.7 \\
(4)\end{array}$ & $\begin{array}{l}96.0 \\
(25)\end{array}$ & $\begin{array}{l}45.7 \\
(58)\end{array}$ & $\begin{array}{c}17.0 \\
(9)\end{array}$ & $\begin{array}{l}68.6 \\
(24)\end{array}$ & $\begin{array}{l}40.0 \\
(8)\end{array}$ & $\begin{array}{c}100.0 \\
(3)\end{array}$ & $\begin{array}{c}50.0 \\
(2)\end{array}$ & $\begin{array}{c}100.0 \\
(12)\end{array}$ \\
\hline & Total & $\begin{array}{l}100.0 \\
(180)\end{array}$ & $\begin{array}{c}100.0 \\
(72)\end{array}$ & $\begin{array}{c}100.0 \\
(41)\end{array}$ & $\begin{array}{c}100.0 \\
(30)\end{array}$ & $\begin{array}{c}100.0 \\
(6)\end{array}$ & $\begin{array}{c}100.0 \\
(6)\end{array}$ & $\begin{array}{c}100.0 \\
(25)\end{array}$ & $\begin{array}{l}100.0 \\
(127)\end{array}$ & $\begin{array}{c}100.0 \\
(53)\end{array}$ & $\begin{array}{c}100.0 \\
(35)\end{array}$ & $\begin{array}{c}100.0 \\
(20)\end{array}$ & $\begin{array}{c}100.0 \\
(3)\end{array}$ & $\begin{array}{c}100.0 \\
(4)\end{array}$ & $\begin{array}{c}100.0 \\
(12)\end{array}$ \\
\hline
\end{tabular}

Dash means no activity; N.A.: Not applicable

Pharmacists declared that $24.8 \%$ and $21.7 \%$ of the PW had been using prescribed and non-prescribed drugs, respectively when PW learnt their pregnancy. Based on the opinion of pharmacists, it was detected that during their pregnancies, $84.1 \%, 9.9 \%$ and $30.8 \%$ of the PW used prescribed, non-prescribed, and nonpharmacological products, respectively. It was also stated that $50.7 \%$ of the PW worried about drug usage during their gestations. These findings were similar in re-examination.

The half of the pharmacists $(50.6 \%)$ stated that they dispensed a non-prescription medicine if requested by PW. Pharmacists declared that most of the drugs (66.4\%) dispensed to PW were risk-free in teratogenicity, whereas those with moderate- or high-risk constituted $9.3 \%$ and $5.7 \%$, respectively. Pharmacists were detected to give similar responses in the re-examination.

Only $12.6 \%$ and $7.4 \%$ of the pharmacists stated that they had encountered drug-induced miscarriage/abortion (due to warfarin, ciprofloxacin, norethisterone, famotidine, fluconazole, and trimethoprim/sulfamethoxazole) and congenital abnormalities (due to diazepam, thalidomide, and an unknown antifungal), respectively. The attitudes of pharmacists during encountering PW prescription was shown at Table 4.

In general, most of the pharmacists declared that they considered and provided information about the dosage and administration route. In addition, they declared that they encountered with prescription errors, especially in writing of script. Similar findings were also observed in the re-examination.

Pharmacists pointed out that the most frequently used sources were electronic drug information services (30.5\%) and internet search engines (21.2\%) while offering a drug for the PW. In addition, majority of the pharmacists $(90.5 \%)$ declared that they want to receive clinical pharmacology information support service. 
Table 3. The distribution of the physicians' attitudes about treatment management, giving information to the patients and the most considering criteria during prescribing $(\mathrm{n}=30)$, (Likert Scale; "1-strongly disagree, 2disagree, 3- No idea, 4- Agree, 5-Strongly Agree).

\begin{tabular}{|c|c|c|c|c|c|c|}
\hline & \multirow{2}{*}{ Answers } & 1 & 2 & 3 & 4 & 5 \\
\hline & & $\%$ & $\%$ & $\%$ & $\%$ & $\%$ \\
\hline \multirow{3}{*}{$\begin{array}{l}\text { Physicians' } \\
\text { attitudes } \\
\text { during } \\
\text { prescribing }\end{array}$} & $\begin{array}{l}\text { Prescribing the drugs } \\
\text { specifically wanted by the } \\
\text { patients }\end{array}$ & 53.3 & 26.4 & - & 16.7 & 3.3 \\
\hline & $\begin{array}{l}\text { Providing information to the } \\
\text { patient about their disease }\end{array}$ & - & - & - & 6.7 & 93.3 \\
\hline & $\begin{array}{l}\text { Explain the treatment } \\
\text { objectives }\end{array}$ & - & - & - & 3.3 & 96.7 \\
\hline \multirow{7}{*}{$\begin{array}{l}\text { Considered } \\
\text { criteria } \\
\text { during } \\
\text { prescribing }\end{array}$} & Drug interactions & - & - & - & 6.7 & 93.3 \\
\hline & Liver disorders & - & - & - & 3.3 & 96.7 \\
\hline & Renal disorders & - & - & - & 3.3 & 96.7 \\
\hline & Chronic disorders & - & - & - & 6.7 & 93.3 \\
\hline & Age & - & 3.3 & - & - & 86.7 \\
\hline & Gestational age & - & - & - & - & 100.0 \\
\hline & Reimbursement/income & 3.3 & 3.3 & - & 40.0 & 53.4 \\
\hline \multirow{9}{*}{$\begin{array}{l}\text { Provided } \\
\text { drug-related } \\
\text { information } \\
\text { to the } \\
\text { pregnant } \\
\text { women }\end{array}$} & Name of the drug & 3.3 & - & 3.3 & 13.4 & 80.0 \\
\hline & Pharmaceutical form of drug & 3.4 & - & - & - & 96.6 \\
\hline & Dosage of the drug & - & - & - & 3.3 & 96.7 \\
\hline & Administration route of drug & - & - & - & - & 100.0 \\
\hline & Duration of the treatment & - & - & - & - & 100.0 \\
\hline & Effects of drug & - & - & 3.3 & 13.3 & 83.4 \\
\hline & Adverse effects of drug & - & 3.3 & 3.3 & 20.0 & 73.4 \\
\hline & Warnings & 3.3 & - & - & 20.0 & 76.7 \\
\hline & Teratogenic warnings & - & - & - & 3.4 & 96.6 \\
\hline
\end{tabular}

Dash means no activity; N.A.: Not applicable

\section{DISCUSSION}

This study revealed critical findings regarding the knowledge, attitudes and behaviors of the key stakeholders on drug use in pregnancy. The overlapping of behaviors and attitudes of the physicians and pharmacists on RUM, supported with data on "analyses of PW prescriptions" and "dispensing simulated PW prescriptions" seem to highlight their lack of some important knowledge related to drug use in pregnancy and some problems in their attitudes, behaviors, and self-experiences.

Polypharmacy during pregnancy is undesirable. The lower mean number of drugs $(1.48 \pm 0.73)$ per PW prescription might be considered as a favorable RUM practice in our study, considering scarce data on the literature that reported $1.66 \pm 0.14$ and $2.33 \pm 1.43$ drugs per prescriptions in studies conducted in Pakistan and Oman, respectively $[7,8]$.

The clear and legible writing of the information about the patient and the physician in the prescription is essential for rational prescribing $[9,10]$, even more critical in pregnancy. For instance, it is of primary importance to include "pregnancy diagnosis" and "gestational age" in pregnant prescriptions to prevent potential serious problems. The lack of these areas of information in collected prescriptions was one of the important findings of our study. In fact, expression of the diagnosis/gestation period will help the pharmacist to recognize and correct the use of possible inappropriate medication. Furthermore, failure to specify the gestational age may cause additional problems of communication and clinical evaluation. For instance, the pregnancy risk classification of acetylsalicylic acid and other non-steroidal anti-inflammatory drugs varies depending on their low/high dosage or usage at different trimesters [11]. Therefore, the lack of gestation age 
information may lead to inadequate management of possible risks of drugs in pregnancy. While pharmacists survey implies this negativity to be partially addressed at first sight, the dispensing simulation step indicates questioning of the gestational by pharmacists only up to $10 \%$. These suggest the need for the elimination of this problem, which appears to be contributed by both physicians and pharmacists in the NC in terms of RUM during pregnancy.

Use of the medication by patients at appropriate dose and duration in line with their clinical needs, i.e. WHO's RUM definition [5], requires dispensing of the right medication by pharmacists, which in turn, needs correct specifying of such information in prescriptions as dosage, pharmaceutical form, duration of usage etc. Although physician survey showed the majority of physicians to declare to give their patients such information, this was not reflected much to their behaviors, as indicated by analyzed prescriptions. This irrational behavior was also supported by the pharmacists who stated to come across incomplete usage instructions, or pharmaceutical form or dosage etc. errors. The lack of such particular information about the drugs in the prescriptions increases the likelihood of pharmacists to offer inappropriate drugs to the patients. Although not specifically performed in PW prescriptions, a study in Turkey examined the information of the format of the prescriptions and reported similar concerns to that of our study. The authors also reported that RUM training favorably changed the competencies of physicians in this respect [10]. These findings suggest that key addressees of drug use in the NC also require RUM training in the appropriate context.

The rates of the category-D (2.4-3.3\%) and category-X (3.1-3.3\%) risk drugs in PW prescriptions seem to be higher than those reported in the literature. Notwithstanding the potential methodological differences, category-D medication use was reported to vary by $1.5-3.5 \%$ and category-X use by $0.7-1.1 \%$ in studies from European countries and the United States [12-16], which implies that PW in the NC have been more likely to be exposed to teratogenic drugs with high risk, especially belonging to the category-X. On the other hand, obstetricians stated that only $2.5 \%$ and $0.5 \%$ of the drugs they prescribed were in "intermediate" and "high" teratogenicity risk, respectively; which was much below than the observed in PW prescriptions as intermediate risk (category-C: 16.7\%) and high risk (category-D and X: 6.6\%). This discrepancy may be attributed to their underestimation related with insufficient knowledge about the teratogenicity risks of the drugs. Another explanation might be the fact that the physicians might have hesitated to express the risky drugs they prescribed. This is also supported by the fact that pharmacists' estimates about drugs with intermediate or high risk they dispensed were higher than that in the physicians.

The prescription analysis showed most commonly prescribed drug groups as vitamin-B12 and folate, multivitamins, iron-preparations, anti-inflammatories/antiseptics, and progestogens. While vitamin-B12 use is recommended due to increased need during pregnancy, several aspects of its use should be handled carefully, including different cobalamin forms, duration of use, and total quantity exposed. In particular, the usage of hydroxocobalamin form is not recommended due to toxicity problems posed by its exposure in pregnancy $[17,18]$. The reason for use of vitamin-B12 together with folate is thought to prevent neural tube defects and other congenital anomalies prior to pregnancy and during the first months of pregnancy. On the other hand, it was reported that folate prophylaxis should start at least four weeks before the conception, because the neural tube closes within 28 days after conception [19]. Although folate seemed to be frequently prescribed/dispensed to $\mathrm{PW}$ in our study, appropriate use of this drug by $\mathrm{PW}$ in this critical window needs to be confirmed by further studies.

The use of "non-pharmacological products, e.g. herbal products/supplements" by around one-third of PW was expressed by both physicians and pharmacists with a slight increase after one year. In fact, the use of these products among PW has generally increased in recent years with a wide variation across countries: use of vitamins was reported as 13\% in Saudi Arabia [20], vitamins/mineral supplements as $79 \%$ in Pakistan and $54 \%$ in the US [13,21], and herbal products as 5\%, 58\%, 48\%, and 36\% in Saudi Arabia, United Kingdom, Italy, and Norway [20,22-24]. Since the results of such studies investigating potential adverse effects of herbal products appear controversial [22-24], the use of herbal products during pregnancy remains limited. Lower use of the non-pharmacological products during pregnancy in NC than in most countries in the literature suggests an overall more rational approach in this context. 
Table 4. The distribution of the pharmacists' attitudes during encountering the pregnant prescription, the most encountered problems and the information provided for patients ( $\mathrm{n}=95)$, (Likert Scale; "1-strongly disagree, 2-disagree, 3- No idea, 4- Agree, 5-Strongly Agree).

\begin{tabular}{|c|c|c|c|c|c|c|}
\hline & \multirow{2}{*}{ Answers } & 1 & 2 & 3 & 4 & 5 \\
\hline & & $\%$ & $\%$ & $\%$ & $\%$ & $\%$ \\
\hline \multirow{9}{*}{$\begin{array}{l}\text { Considered } \\
\text { information } \\
\text { during } \\
\text { dispensing } \\
\text { the pregnant } \\
\text { prescription }\end{array}$} & Name of the patient & 6.3 & 16.8 & 1.1 & 37.9 & 37.9 \\
\hline & Age of the patient & 2.1 & 16.8 & 9.5 & 31.6 & 40.0 \\
\hline & Diagnosis & 2.1 & 4.2 & 10.5 & 33.7 & 49.5 \\
\hline & Date of the script & 3.2 & 7.4 & 6.2 & 47.4 & 35.8 \\
\hline & Availability of pregnancy diagnosis & - & 7.4 & 9.4 & 27.4 & 55.8 \\
\hline & Dosage of the drug & - & - & - & 12.6 & 87.4 \\
\hline & Pharmaceutical form & - & 3.1 & - & 15.8 & 81.1 \\
\hline & Administration route of the drug & - & - & - & 12.6 & 87.4 \\
\hline & Duration of treatment & - & - & 1.1 & 20.0 & 78.9 \\
\hline \multirow{9}{*}{$\begin{array}{l}\text { Problems } \\
\text { encountered } \\
\text { in } \\
\text { prescription }\end{array}$} & Pharmaceutical dosage error & 11.6 & 38.9 & 11.6 & 30.5 & 7.4 \\
\hline & Insufficient instruction & 5.3 & 14.7 & 10.5 & 51.6 & 17.9 \\
\hline & Pharmaceutical form error & 5.3 & 31.6 & 14.7 & 44.2 & 4.2 \\
\hline & Medication not available in market & 1.1 & 5.3 & 7.3 & 50.5 & 35.8 \\
\hline & Illegible writing & 2.1 & 9.5 & 7.3 & 29.5 & 51.6 \\
\hline & Drug-drug interactions & 6.3 & 48.4 & 10.6 & 26.3 & 8.4 \\
\hline & Contraindication & 7.3 & 47.4 & 10.5 & 29.5 & 5.3 \\
\hline & Treatment duration error & 3.2 & 44.2 & 10.5 & 27.4 & 14.7 \\
\hline & Inappropriate medication & 12.6 & 55.8 & 6.4 & 16.8 & 8.4 \\
\hline \multirow{10}{*}{$\begin{array}{l}\text { Provided to } \\
\text { the pregnant } \\
\text { women }\end{array}$} & Diagnosis & 3.2 & 26.3 & 6.3 & 34.7 & 29.5 \\
\hline & Pharmaceutical dosage of drug & - & 3.2 & 1.1 & 18.9 & 76.8 \\
\hline & Administration route of drug & - & - & - & 11.6 & 88.4 \\
\hline & Taking the drug empty/full stomach & - & - & 1.1 & 9.5 & 89.5 \\
\hline & Duration of treatment & - & 1.1 & 1.1 & 20.0 & 77.9 \\
\hline & Storage conditions of the drug & - & - & 3.2 & 26.3 & 70.5 \\
\hline & Adverse effects of the drug & 1.1 & 7.4 & 5.2 & 40.0 & 46.3 \\
\hline & Drug-drug interactions & 1.1 & 7.4 & 11.5 & 38.9 & 41.1 \\
\hline & Drug-food interactions & - & 9.5 & 7.4 & 36.8 & 46.3 \\
\hline & Possible effects of drug on fetus & 2.1 & 21.1 & 10.5 & 32.6 & 33.7 \\
\hline
\end{tabular}

Dash means no activity; N.A.: Not applicable

Drug use during pregnancy may lead to miscarriage, abortion, or congenital anomalies [14,15,25,26]. The majority of the physicians $(70 \%)$ reported to encounter drug-induced miscarriage/abortion, which they mostly related to ciprofloxacin and tetracyclines. In fact, the use of these drugs are not recommended in pregnancy due to the association with congenital abnormalities $[25,26]$. Statements of physicians regarding abortion cases due to such drugs indicate the need for uplifting awareness among relevant parties.

The observed dispensing time of the pharmacist with a decreasing trend towards the second examination (3.3 to $2.0 \mathrm{~min}$ ) seems consistent with that $(2.5 \mathrm{~min}$ ) in simulation studies conducted in the NC and Turkey $[27,28]$. Nevertheless, these appear comparably lower than WHO recommendations of at least 3 minutes [29], especially considering that this period is expected to extend further in case of dispensing pregnant prescription. The simulations showed half of the pharmacists to meet the non-prescribed "trimethobenzamide" requests of the simulated PW in both examinations. Used for antiemetic purposes in 
pregnancy, trimethobenzamide is a "category-C" drug with reported toxicity in rats yet no evidence of teratogenicity in clinical practice, suggesting that this drug can only be used if there is no other alternative [30]. Dispensing of a category-C drug by one in every two pharmacists in the absence of any prescription indicates that they have the potential to offer inappropriate medicine in pregnancy. This negative behavior was further complicated by their almost total failure to provide information about the pharmaceutical form, strength, dose, and duration of the drug during simulations, contradictory to their statements in the survey. Indeed, this conflict was observed in most part of the pharmacist survey and simulated pregnancy prescription data. Contrary to our findings, a previous study conducted in the NC reported near three-fourths of pharmacists to give dose information to simulated patient [28]. A study from Lithuania reported that pharmacists provided information to their patients about the effects, adverse effects, and risks associated with their use during pregnancy [31]. Similar to our findings, a study conducted in Turkey detected that pharmacists do not provide enough information to the patients about the drugs they offer [27]. On the other hand, observed attempts (40-46\%) to offer an alternative anti-emetic by pharmacists in the simulation has several implications. Not only it was higher than that reported (11\%) in a simulation study in Turkey [28], but also none of the mostly offered alternatives, i.e. ondansetron, diphenhydramine, or metoclopramide, was the equivalent of the prescribed "vitamin/mineral containing-antiemetic". Although the drugs such as ondansetron and metoclopramide recommended as equivalent are not directly teratogenic, they are not the first-choice drugs for the treatment of nausea/vomiting in pregnancy [32,33]. Dispensing inappropriate drugs with no or scarce drug information overall suggest an irrational behavior cluster of pharmacists in the NC in encountering PW prescriptions.

Overall, the shortcomings of observed in this study indicate the need for dissemination of RUM activities for both physicians and pharmacists in the NC. In fact, undergraduate RUM education was reported to have positive impact on prescribing and pharmacotherapy practices in the primary care [10,34]. A similar model was also reported to be successful for pharmacy students [35].

Our study has some limitations. The absence of the "pregnancy" diagnosis in PW prescriptions in NC led us to obtain less prescriptions than expected. Besides, as most of the PW prescriptions we analyzed did not include any diagnosis, we could not evaluate indication-drug relation and rational drug selection. Next, the data collected on surveys were just based on participants' expressions. Nevertheless, prescription analysis and simulation practice have helped to confirm the statements of the physicians and pharmacists, respectively; though all questions could not be covered. Finally, detection of drug-induced teratogenicity problems in risky groups requires follow-up during pregnancy and post-partum period. The failure of follow-up of the patients who received category-D/X drugs may also be regarded as another limitation of this study. This could be overcome by designing further studies that investigate the effects of the use of these risky drugs on fetuses and/or babies in NC.

\section{CONCLUSION}

Our study highlighted the deficiencies in the knowledge, attitudes, and behaviors regarding RUM in pregnancy for both physicians and pharmacists in the NC, where the gaps seems unchanged after one year. Physicians seem to exhibit irrational prescribing habits such as both in format and content with a higher tendency to prescribe drugs at moderate/high risk of teratogenicity contrary to their statements. Pharmacists, on the other hand, appear to encounter the non-prescribed drug request by patients or to offer a nonequivalent alternative drug without providing sufficient information. It is thought that a considerable part of the problems related to drug use in pregnancy among the health care professionals is due to the lack of clinical pharmacology consultancy services. These findings are expected to be a guide in the dissemination of RUM during pregnancy in both the NC and other countries. 


\section{MATERIALS AND METHODS}

In this pharmaco-epidemiological study, the data were obtained by (1) analyzing PW prescriptions, (2) evaluating pharmacists' dispensing performance for simulated PW prescriptions, and (3) conducting surveys for obstetricians and pharmacists between April 2016 and July 2017 in NC.

\subsection{Prescription analysis}

A total of 122 obstetrician prescriptions were collected from six pharmacies located near private and/or state hospitals. The prescribing performance of physicians was analyzed in terms of the content and the format of the scripts. The "Anatomical and Therapeutic Chemical" (ATC), (at the level as ATC-1, 3 and 5) and United States "Food and Drug Administration (FDA) pregnancy risk category" classifications were used to evaluate the prescribed medicines for PW [36]. FDA pregnancy categories were primarily checked from the product's information leaflet / monographic information, if any, and from an online database if the relevant official documents of the product did not have this information.

\subsection{Dispensing of simulated prescriptions at pharmacies}

After obtaining a permission from the national health authority, fifty community pharmacies $(27.2 \%$ of the registered pharmacies) located in all main settlements in the NC and selected randomly were challenged with a simulated prescription for PW. This process was completed before the pharmacists answered the survey. The three simulating PW aged 28 to 33 years old had received previous training by a single researcher to act a standardized role and accompanied an observer to collect the required data of the simulation. Observations were transferred to a standard checklist right after leaving the pharmacy. During the prescription dispensing period, the simulating patient asked for trimethobenzamide (a prescription-only drug) instead of the prescribed drug (a vitamin/mineral combination indicated for emesis). The simulated patient purchased the drug, whose cost was covered by the investigators. In this way, the attitude and behaviors of the pharmacist were evaluated. In all those pharmacies, it was the pharmacist who met the demand of the patient.

\subsection{Physician and pharmacist surveys}

The face-to-face self-structured surveys consisted of questions ( $\mathrm{n}=26$ for both) regarding these participants' demographic and occupational characteristics, their observations and attitudes about the PW they served, and their knowledge on use of medicines in pregnancy.

All the data of this study were repeated in the same order to detect possible differences one year later. For this study, a protocol was established with the Health Ministry of the NC and an ethical approval was obtained from the Ethics Committee of Marmara University Health Sciences Institute (Approval no: 241, 28.03.2016-8). The collected data were analyzed by statistical software SPSS (version 15.0). Categorical and continuous variables were expressed as number/percentage and mean/standard deviation, respectively. The comparisons between groups were analyzed via t-test, chi-square test, or McNemar test, where appropriate. An overall 5\% type-I error level was used to infer statistical significance.

Acknowledgements: Due to their contribution of the study to the design and collection of some the data, we would like to thanks pharmacist M. Soyalan, Dr. S. Soysal, Dr. S. İzbul and F. Sucuoğlu.

Author contributions: Concept - M.T., A.A., M.Z.G., V.A., S.S.; Design - M.T., A.A., M.Z.G., V.A., S.S.; Supervision A.A., M.Z.G., S.S., V.A.; Resources - M.T.; Materials -; Data Collection and/or Processing - M.T.; Analysis and/or Interpretation - M.T., A.A.; Literature Search - M.T.; Writing - M.T.; Critical Reviews - M.T., A.A., V.A., M.Z.G., S.S.

Conflict of interest statement: The authors declared no conflict of interest.

Ethics committee approval: Ethics Committee of Marmara University Health Sciences Institute approved studies with approval number of 241, 28.03.2016-8. 


\section{REFERENCES}

[1] Olesen C, Thrane N, Henriksen TB, Ehrenstein V, Olsen J. Associations between socio-economic factors and the use of prescription medication during pregnancy: a population-based study among 19,874 Danish women. Eur J Clin Pharmacol. 2006; 62(7): 547-553. [CrossRef]

[2] Başgül A, Akici A, Uzuner A, Kalaça S, Kavak ZN, Tural A, Oktay S. Drug utilization and teratogenicity risk categories during pregnancy. Adv Ther. 2007; 24(1): 68-80. [CrossRef]

[3] Lupattelli A, Spigset O, Twigg MJ, Zagorodnikova K, Mardby AC, Moretti ME, Drozd M, Panchaud A, HameenAnttila K, Rieutord A, Juraski RG, Odalovic M, Kennedy D, Rudolf G, Juch H, Passier A, Björnsdottir I, Nordeng H. Medication use in pregnancy: across-sectional, multinational web-based study. BMJ Open. 2014; 4(2): e004365. [CrossRef]

[4] Pisa FE, Casetta A, Clagnan E, Michelesio E, Brumatti LV and Barbone F. Medication use during pregnancy, gestational age and date of delivery: agreement between maternal self-reports and health database information in a cohort. BMC Pregnancy and Childbirth. 2015; 15: 310. [CrossRef]

[5] WHO. The rational use of drugs: report of the conference of experts. World Health Organization; Nairobi, 25-29 November 1985. ISBN 924156105 X

[6] State Planning Organization. Population and indicators. http://www.deoplan.org/Frame-tr.html (accessed on 09 June 2020)

[7] Rohra DK, Das N, Azam SI, Solangi NA, Memon Z, Shaikh AM and Khan MH. Drug prescribing patterns during pregnancy in tertiary care hospitals of Pakistan: a cross sectional study. BMC Pregnancy and Childbirth. 2008; 8: 15. [CrossRef]

[8] Al-Hamimi and Al Balushi KA. Patterns of prescription drugs use among pregnant women at Sultan Qaboos University Hospital and Sultan Qaboos University Hospital Family and Community Medicine Clinic, Oman. J Pharm Bioallied Sci. 2006; 8(4): 309-313. [CrossRef]

[9] De Vries TP, Henning RH, Hogerzeil HV, Fresle DA. Guide to good prescribing. A practical manual. Geneva: WHO/DAP/94.11. World Health Organization. Action Programme on Essential Drugs. 1994; 6-75.

[10] Akici A, Kalaça S, Uğurlu MU, Karaalp A, Çali Ş ve Oktay Ş. Impact of a short postgraduate course in rational pharmacotherapy for general practitioners. Br J Clin Pharmaocol. 2004; 57(3): 310-321. [CrossRef]

[11] Bloor M, Paech M. Nonsteroidal anti-inflammatory drugs during pregnancy and the initiation of lactation. Anesth Analg. 2013; 116(5): 1063-1075. [CrossRef]

[12] Lee E, Maneno MK, Smith L, Weiss SR, Zuckerman IH, Wutoh AK and Xue Z. National patterns of medication use during pregnancy. Pharmacoepidemiol Drug Saf. 2006; 15(8): 537-545. [CrossRef]

[13] Andrade SE, Gurwitz JH, Davis RL, Chan KA, Finkelstein JA, Fortman K, McPhillips H, Raebel MA, Roblin D, Smith DH, Yood MU, Morse AN, Platt R. Prescription drug use in pregnancy. Am J Obstet Gynecol. 2004; 191(2): $398-407$. [CrossRef]

[14] Andrade SE, Raebel MA, Morse AN, Davis RL, Chan KA, Finkelstein JA, Smith DH, Yood MU, Platt R and Gurwitz $\mathrm{JH}$. Use of prescription medications with a potential for fetal harm among pregnant women. Pharmaco-epidemiol. Drug Saf. 2006; 15(8): 546-554. [CrossRef]

[15] Zomerdijk IM, Ruiter R, Houweling LMA, Herings RMC, Straus SMJM, Stricker BH. Dispensing of potentially teratogenic drugs before conception and during pregnancy: a population-based study. BJOG. 2015; 122(8): 1119-1129. [CrossRef]

[16] Gagne JJ, Maio V, Barghella V, Louis DZ, Gonnella JS. Prescription drug use during pregnancy: a population-based study in regione Emilia-Romagna, Italy. Eur J Clin Pharmacol. 2008; 64(11): 1125-1132. [CrossRef]

[17] Meridian Medical Technologies. Product Information: Cyanokit(R) IV injection, hydroxocobalamin IV injection. Meridian. Medical. Technologies, Inc, Columbia, MD, 2011.

[18] Picciano MF. Pregnancy and lactation: Physiological adjustments, nutritional requirements and the role of dietary supplements. J Nutr. 2003; 133(6): 1997S-2002S. [CrossRef]

[19] Egen-Lappe V, Hasford J. Drug prescription in pregnancy: analysis of a large statutory sickness fund population. Eur J Clin Pharmacol. 2004; 60(9): 659-666. [CrossRef]

[20] Zaki NM, Albarraq AA. Use, attitudes and knowledge of medications among pregnant women: A Saudi Study. Saudi. Pharm. J. 2014; 22(5): 419-428. [CrossRef] 
[21] Rohra DK, Das N, Azam SI, Solangi NA, Memon Z, Shaikh AM and Khan MH. Drug prescribing patterns during pregnancy in tertiary care hospitals of Pakistan: a cross sectional study. BMC Pregnancy and Childbirth. 2008; 8: 24. [CrossRef]

[22] Holst L, Wright D, Haavik S, Nordeng H. The use and the user of herbal remedies during pregnancy. J Altern Complement Med. 2009; 15(7): 787-792. [CrossRef]

[23] Lapi F, Vannacci A, Moschini M, Cipollini F, Morsuillo M, Gallo E, Banchelli G, Cecchi E, Di Pirro M, Giovannini MG, Cariglia MT, Gori L, Firenzuoli F, Mugelli A. Use, attitudes and knowledge of complementary and alternative drugs (CADs) among pregnant women: a preliminary survey in Tuscany. Evid Based Complement Alternat Med. 2008; 7(4): 477-486. [CrossRef]

[24] Nordeng H, Havnen GC. Use of herbal drugs in pregnancy: a survey among 400 Norwegian women. Pharmacoepidemiol Drug Saf. 2004; 13(6): 371-380. [CrossRef]

[25] Schaefer C, Amoura-Elefant E, Vial T, Ornoy A, Gabris H, Robert E, Rodriquez-Pinilla E, Pexieder T, Prapas N and Merlob P. Pregnancy outcome after prenatal quinolone exposure: evaluation of a case registry of the European network of teratology information services (ENTIS). Eur J Obstet Gynecol Reprod Biol. 1996; 69(2): 83-89. [CrossRef]

[26] Koren G. Special Aspects of Perinatal \& Pediatric Pharmacology. Katzung BG. (Eds). Basic and Clinical Pharmacology. McGraw Hill, 2012, pp:1041.

[27] Toklu HZ, Akici A, Oktay S, Cali S, Sezen SF, Keyer-Uysal M. The pharmacy practice community pharmacists in Turkey. Marmara Pharm J. 2010; 14(1): 53-60. [CrossRef]

[28] Gokcekus L, Toklu HZ, Demirdamar R, Gumusel B. Dispensing practice in the community pharmacies in the Turkish Republic of Northern Cyprus. Int J Clin Pharm. 2012; 34(2): 312-324. [CrossRef]

[29] Santos VD, Nitrini O. Prescription and patient-care indicators in healthcare services Rev. Saude Publica. 2004; 38(6): 819-826. [CrossRef]

[30] Erol AYG, Gokcimen A, Ozdemir O. Growth failure, tardive dyskinesia, megacolon development, and hepatic damage in neonatal rats following exposure to trimethobenzamide in utero. J Matern Fetal Neonatal Med. 2011; 24(9): 1176-1180. [CrossRef]

[31] Grinceviciene S, Kubiliene L, Ivanauskas K, Drasutiene GS, Ramasauskaite D, Grincevicius J, Bernatoniene J, Savickas A. Experiences of community pharmacists advising pregnant women. Int J Clin Pharm. 2015; 37(4): 636-644. [CrossRef]

[32] Carstairs SD. Ondansetron use in pregnancy and birth defects: A systemic review. Obstet. Gynecol. 2016; 127(5): 87883. [CrossRef]

[33] Zambelli-Weiner A, Via C, Yuen M, Weiner DJ, Kirby RS. First trimester ondansetron exposure and risk of structural birth defects. Reprod Toxicol. 2019; 83: 14-20. [CrossRef]

[34] Akici A, Kalaça S, Gören MZ, Akkan AG, Karaalp A, Demir D. Comparison of rational pharmacotherpy decisionmaking competence of general practitioners with intern doctors. Eur J Clin Pharmacol. 2004; 60(2): 75-82. [CrossRef]

[35] Toklu HZ and Demirdamar R. The evaluation of prescription dispensing scores of the pharmacy students before and after the problem-based "rational drug use" course: Results of the two years' experience. Marmara Pharm J. 2013; 17: 175-180. [CrossRef]

[36] Briggs GG., Freeman RK., Yaffe SJ, Drugs in pregnancy and lactation, fourth ed., Baltimore, Williams \& Wilkins. 1994. 